\title{
Characterization and Comparison of Rheological Properties of Agro Fiber Filled High-Density Polyethylene Bio-Composites
}

\author{
Anselm O. Ogah ${ }^{1 *}$, Joseph N. Afiukwa ${ }^{2}$, A. A. Nduji ${ }^{2}$ \\ ${ }^{1}$ Composite Materials \& Engineering Center, Washington State University, Pullman, USA \\ ${ }^{2}$ Department of Industrial Chemistry, Ebonyi State University, Abakaliki, Nigeria \\ Email: "ogaha2007@yahoo.com
}

Received January 3, 2014; revised February 3, 2014; accepted February 9, 2014

Copyright (C) 2014 Anselm O. Ogah, et al. This is an open access article distributed under the Creative Commons Attribution License, which permits unrestricted use, distribution, and reproduction in any medium, provided the original work is properly cited. In accordance of the Creative Commons Attribution License all Copyrights (c) 2014 are reserved for SCIRP and the owner of the intellectual property Anselm O. Ogah, et al. All Copyright (C) 2014 are guarded by law and by SCIRP as a guardian.

\section{ABSTRACT}

The rheological behavior of composites made with high-density polyethylene (HDPE) and different agro fiber by-products such as corncob (CCF), Rice hull (RHF), Flax shives (FSF) and Walnut shell (WSF) flour of 60 - 100 mesh were studied. The experimental results were obtained from samples containing 65 vol.\% agro fiber and 3 wt.\% lubricant. Particle sizes distribution of the agro fibers was in the range of $0.295 \mathrm{~mm}$ to $<0.125 \mathrm{~mm}$. SEM showed evidence of complete matrix/fiber impregnation or wetting. The melt rheological data in terms of complex viscosity $\left(\eta^{*}\right)$, storage modulus $\left(G^{\prime}\right)$, loss modulus $\left(G^{\prime \prime}\right)$, and loss tangent $(\tan \delta)$ were evaluated and compared for different samples. Due to higher probability of agglomeration formation in the samples containing 65 vol.\% of agro fillers, the storage modulus, loss modulus and complex viscosity of these samples were high. The unique change in all the samples is due to the particle size distribution of the agro fibers. The storage and loss modulus increased with increasing shear rates for all the composites, except for Walnut shell composite which exhibited unusual decrease in storage modulus with increasing shear rate. Damping factor $(\tan \delta)$ decreased with increasing shear rate for all the composites at $65 \mathrm{vol} . \%$ filler load although there were differences among the composites. Maximum torque tended to increase at the $65 \mathrm{vol}$ \% agro fiber load for all composites. Corncob and Walnut shell composites gave higher torque and steady state torque values in comparison with Flax shives and Rice hull composites due to differences in particle sizes distribution of the agro fibers.

\section{KEYWORDS}

Melt Rheology; Agro Fiber; Bio-Composites; Viscoelasticity; High-Density Polyethylene

\section{Introduction}

Wood-polymer composites (WPC) and in general natural fiber composites (NFC) have received considerable attention during the last decade. Their popularity stems from the fact that natural fillers represent low-cost renewable reinforcements that enhance mechanical properties such as stiffness, strength, and heat deflection temperature under load [1]. Natural fiber composites are widely used for decking and automotive applications, as well as a building material, where the relatively low den-

\footnotetext{
"Corresponding author.
}

sity of the natural fillers is a major advantage. Most of the work being done on WPC/NFC is dedicated to investigation of the impact fracture and deformation behavior as well as influence of various additives on the mechanical properties, aging and durability [2]. Along with the improvements that wood fillers bring to the matrix polymer, their addition also results in reduced ductility and poor impact resistance [3]. Furthermore, addition of wood fillers to thermoplastic polymers is accompanied by a considerable increase in the melt viscosity [4-7].

Despite the rapid growth of using wood plastic composites (WPC) in automotive and other industries, espe- 
cially at North America, the published information in the field of rheology of WPC is few. Rheology can interpret degree of dispersion of wood fiber, behavior of interfacial region, and polymer-wood fiber affinity and has a vital role in processing of these composites [8-10]. Both capillary and oscillatory rheometers have been reported to generate rheological data for WPC. Because of migration (from wall to center) and breaking of wood fibers at high shear rates in capillary rheometer, using of dynamic oscillatory technique is recommended [11,12]. Maiti et al. [13] studied the effect of wood flour (WF) concentration on the rheological behavior of isotactic-polypropylene (i-PP)/wood composite in capillary rheometer. They showed that the shear stress rate variation obeys a power law equation, and the composite exhibited shear thinning property with increasing filler content [10]. The effect of wood fiber modification by various methods such as corona, silane, isocyanate treatment and using of coupling agent on mechanical and rheological properties of WPC has been reported, and results indicated that depending on strength of interaction, viscosity increases or decreases [14-16]. Li et al. [17] studied the influence of lubricant on rheological behavior of WF-filled polypropylene (PP) composite. Their results showed that the addition of internal lubricant is effective in reducing apparent viscosity, which tends to increase with adding of WF. The dynamic mechanical and thermal properties of modified PP/WF composite have been investigated by Hristov and Vasileva [18]. The authors in the other papers studied the viscoelastic behavior, surface tearing, and wall slip phenomena of highly filled high density polyethylene (HDPE)/WF composites $[19,20]$. The rheological behavior of HDPE/WF composite under the steady shear and extensional flow has been studied by Li and Wolcott [21]. They found that the extensional viscosity does not get affected by wood content significantly. They also analyzed the wall slip of composite and reported that the rate of this phenomenon is influenced by wood content [22]. These authors in another paper studied the effect of the wood content, particle size, and maleated polyethylene on the rheological properties of maple/HDPE composite [23].

The elastic component is given by the dynamic storage modulus which indicates the inherent stiffness of the material while the mechanical damping or internal friction $(\tan \partial)$ shows the amount of energy dissipated as heat during the deformation [24]. From the industrial and structural point of view, the damping parameter is important due to environmental concerns because application of a high damping material to a vibrating surface converts the energy to heat which is distributed within the material itself and is not radiated as airborne noise. Thus, in structural applications where sound or any other kind of vibration absorption is needed a high damping or internal friction is required which decreases the effect of undesirable vibration to safer limits. The studies on the melt flow properties of the filled polymer system are important in order to establish better processing conditions and maximize the product performance. Rheological measurements conducted in various steady-state and dynamic environments are used widely for determining the sensitivity of a material during processing [25]. Generally, the presence of filler in thermoplastic and elastomers increases the melt viscosity and may result in unusual rheological effects. The rheological studies of polymeric composites have been carried out extensively by these workers [26-28].

In the present investigation, a parallel plate rotational rheometer is used to characterize rheologically composites made by HDPE and different agro fiber by-products such as Corncob, Rice hull, Flax shives and Walnut shell samples containing 65 vol.\% filler load, and 3 wt.\% lubricant. The effect of particle size distribution of the agro fibers by-products on the rheological behavior of these composites is examined.

\section{Materials and Methods}

\subsection{Material}

The polymeric matrix used was HDPE (HP54-60) of density $0.95 \mathrm{~g} / \mathrm{cm}^{3}$, (melt flow index) MFI $=0.35 \mathrm{~g} / 10 \mathrm{~min}$. Agro fiber by-products such as Corncob, Rice hull, Flax shives and Walnut shell flour (60 - 100 mesh) was used as received from the manufacturers and sieve analysis was conducted on oven dried (OD) fibers (100 g) using a Mechanical Sieve Shaker (Model Rx-86) with standard test sieves $(50,60,70,80,100,120$ mesh and pan) for $10 \mathrm{~min}$, according to the Rotap A method (ASTM D5644-010).

\subsection{Sample Preparation}

Agro fibers by-products such as corn cob, rice hull, walnut shell and flax shive flour at 65 vol.\% proportions, high-density polyethylene at 32 vol.\% proportion and lubricant (WP4400) at 3 wt.\% were compounded using the Haake and capillary rheometer to make the 2-mm thick discs samples for the rheological tests.

\subsection{Rotational Rheometry}

The melt rheological properties were determined using a discovery (HR-2) hybrid rotational rheometer by TA Instruments under strain-controlled conditions. The plate diameter is $25 \mathrm{~mm}$ and the gap between plates was set to $1.5 \mathrm{~mm}$. 2-mm thick disc test samples having the same diameter as the rheometer plates were prepared on a HAAKE Rheomix 3000 internal mixer at $170^{\circ} \mathrm{C}$ for 10 min. The samples were put between the plates and heated to $170^{\circ} \mathrm{C}$ for 3 min to eliminate previous thermal history. 
After adjusting the gap to $1.5 \mathrm{~mm}$, the squeezed molten material was carefully trimmed off for attaining smooth edge surface. Dynamic frequency sweeps were carried out from 0.1 to $100 \mathrm{rad} / \mathrm{s}$ range at a strain within the linear viscoelastic region (LVR) of the materials. The strain was kept constant at $0.02 \%$ over the whole frequency range to ensure linearity. This strain was selected from a dynamic strain-sweep test, in which, within $0.001 \%-10 \%$ strains, at a fixed frequency of $10 \mathrm{rad} / \mathrm{s}$, the deviation strain from linearity was tracked; then frequency sweep test was done at constant temperature. The temperature was $170^{\circ} \mathrm{C}$ and the frequency, $\omega$, varied between 0.1 to $100 \mathrm{rad} / \mathrm{s}$. Each measurement was performed on a fresh sample, and repeated measurements had been conducted to ensure the reproducibility of the experimental results.

\section{Results and Discussions}

\subsection{Torque Rheometry}

Figure 1 showed the torque rheometry curves of agro fiber/HDPE composites. A 65 wt.\%, 32 wt.\% and 3 wt.\% of $50 \mathrm{~g}$ of CCF, RHF, WSF and FSF, HDPE and a lubricant were compounded using a torque rheometer to provide quantitative information on compounding of agro fiber/HDPE composites. Torque rheometry data examined were maximum torque and steady state torque as indicators of agro fiber/HDPE compounding. Maximum torque tended to increase at the 65 vol.\% filler load for all the agro fiber HDPE composites. Results for agro fiber formulations show that at 65 vol.\% filler load the maximum torque and the steady state torque recorded decreased with a decrease in agro fiber sizes. Corncob and Walnut shell composites gave higher torque and steady state torque values when compared with Flax shives and Rice hull composites due to their differences in particle size distribution. In all cases, an initial loading peak was registered at the beginning of the experiment, reflecting the high viscosity of the HDPE/agro fiber blends. The sharp increase in torque was due to the plunger pushing all the material into the chamber, which caused the blends to melt and provided less resistance, resulting in lower torque values. It is observed that Flax shives and rice hull fillers were dispersed in the polymer matrix within 2 - 4 min of mixing time, while corncob and Walnut shell fillers took 4 - 6 min to be dispersed. This implies that at the same filler load Corncob and Walnut shell agro fibers displayed higher torque value than Flax and Rice hull agro fibers [29,30].

\subsection{Strain Sweep Test}

Figure 2 showed the strain sweep test of the agro fiber/ HDPE composites. It could be seen that the storage mod-

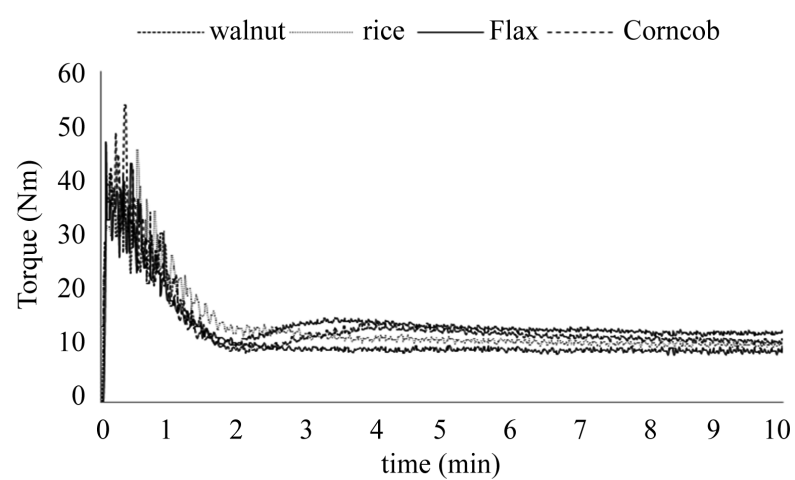

Figure 1. Torque rheometry curves of agro fiber/HDPE composites.

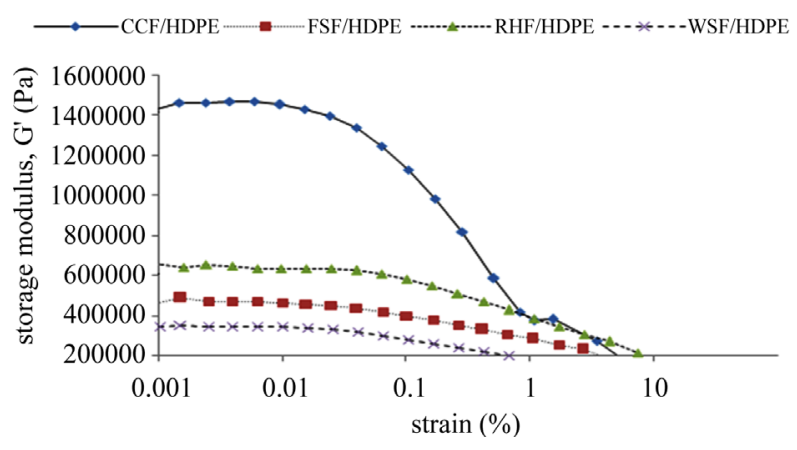

Figure 2. Storage modulus versus strain.

ulus, G', of the agro fiber composites changed within the entire strain range. Highly filled composites (up to 65\% agro fiber load) showed relatively high resistance to deformation. At $0.001 \%$ stain, CCF/HDPE gave a storage modulus of 1,460,000 GPa, RHF/HDPE gave a storage modulus of $640,000 \mathrm{GPa}, \mathrm{FSF} / \mathrm{HDPE}$ gave a storage modulus of 490,000 GPa and WSF/HDPE gave a storage modulus of 350,000 GPa respectively. At strains above $0.02 \%$, however, it was seen that $\mathrm{G}^{\prime}$ decreased, which is a sign of possible change in the composite structure. It is interesting to note that the strain, at which the storage modulus sharply dropped down, varies from one agro fiber composite to another. This is attributable to the differences in particle size distribution of the different agro fibers. These results are in agreement with the results of Marcovich et al. [31], Li and Wolcott [32] for wood filled polymer composites. The reduction in the storage modulus with increased strain indicated the breakage of the material structure. The reason for the structure breakage at high dynamic strains could be attributed to the incompatibility and poor adhesion between the matrix and agro fiber fillers [33]. Progressively increasing strain generated high shear stresses that cannot be transferred through the interface (because of the poor adhesion), and the deformation energy cannot be effectively absorbed by the agro filler particles. 


\subsection{Complex Viscosity of Composite}

Figure 3 showed the variation of complex viscosity with frequency for the agro fiber/HDPE composites. It was well established that the addition of filler into the polymer matrix increased the viscosity of the melt. The rigid agro fiber particles may disturb the flow and provide obstruction to flow of the polymer melt, thus causing a rise in viscosity. The increased viscosity depends on the concentration, particle size distribution and shape of the fillers. The highest complex viscosity was related to the HDPE containing 65\% (by vol.) Corncob fiber. In addition, the presence of agglomerates (due to high filler load) in the agro fillers caused resistance against the flow and increased viscosity of composites. It was noticed that at $0.1 \mathrm{rad} . / \mathrm{s}$ the complex viscosity of WSF, FSF and RHF based composites are about 380,000 Pa.s while that of CCF/HDPE samples is about 3,600,000 Pa.s respectively. The pseudo lubricant effect could explain the reduction in the complex viscosity with respect to other samples when comparing with CCF composites. There was a steady decrease in complex viscosity of all samples with increased shear rate (frequency); which means that the agro fibers exhibited shear thinning behavior (pseudo plasticity) [19,23,34,35]. A higher number of smaller particles results in more particle-particle interactions and an increased resistance to flow as is the case with Corncob flour. Increase particle size distribution and viscosity will decrease as is the case with Flax shives and Rice hull flours. In a constant volume fraction (65\%), the number of particles will increase when particle size decreases. As a result of this, the number of interaction between particles increases as well (the resistance to force that causes flow). The effect is more common at low shear rates, as a particle-particle interaction is a weak force. Decrease particle size and viscosity will increase. Increase particle size and viscosity will decrease [36]. At 65\% (by vol.) agro fiber load it stands to reason that if you were to increase the particle size, this would lead to a lower amount of particle-particle interaction, resulting in a decrease in viscosity as is the case with Flax shives and Rice hull flours. As before, this effect is most common at low shear rates. Increase particle size distribution and viscos-

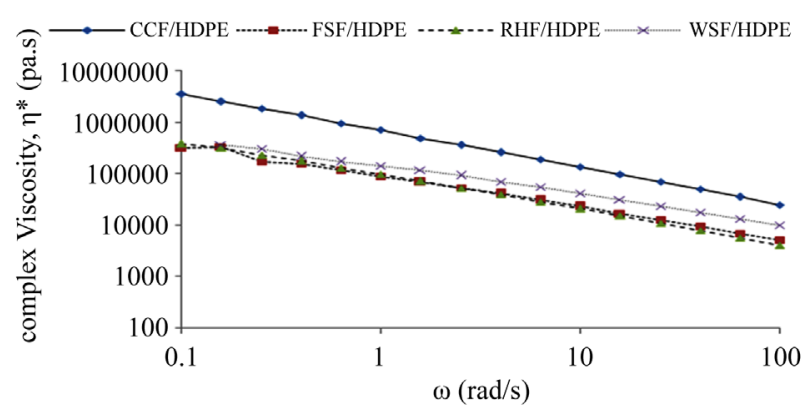

Figure 3. Complex viscosity versus frequency. ity will decrease. Particles with a wider size distribution or "span" will generally pack better than a particle system of uniform size. Essentially, a wide particle distribution will have a larger amount of free space to roam, meaning sample flow becomes easier (i.e., there is a lower viscosity) such is the case with Flax shives and Rice hull flours. If keeping the same volume fraction (65\%) of agro filler load the viscosity of a sample of larger particles with a small proportion of smaller particles will be lower than a small or large particle on its own. The reason for this is the two competing effects of altering the span and also altering the number of particle-particle interactions. Lubricants significantly increase the output, widen the processing window, and lower the melt temperature. They are widely used in the extrusion of linear polyolefin's to prevent sharkskin, flow instability, and melt fracture $[37,38]$.

\subsection{Storage Modulus of Composites}

Figure 4 showed the variation of the storage modulus versus frequency. Due to high agro fiber load of $65 \%$ by volume (causing agglomeration) and the intrinsic rigidity of the agro fibers, the storage modulus of composites were high. It should be noted that addition of fibers may lead to changes in the relaxation time spectrum resulting in changes in viscoelastic properties. Formation of polymer-filler network is the reason for changing storage modulus. This phenomenon can be described as follows: With high agro fiber load enhanced discontinuity may result in the squeezing out the polymer to the surface, which creates continuity on the surface. In other words, at high agro fiber load (65\%) because of the presence of agro fibers in the bulk of the melt, the discontinuity increases and because of different polarity between agro fibers and HDPE, migration of polymer to surface occurs and continuity at the surface increases. This conformation retains even when the melt exit the die. This continuity facilitates elastic energy recovery and increases the melt elasticity [39]. The storage modulus was 650,000 GPa for WSF/HDPE, 280,000 GPa for CCF/HDPE, 25,000 GPa for RHF/HDPE and FSF/HDPE at $0.1 \mathrm{rad} / \mathrm{s}$. As frequency increased, the storage modulus differences

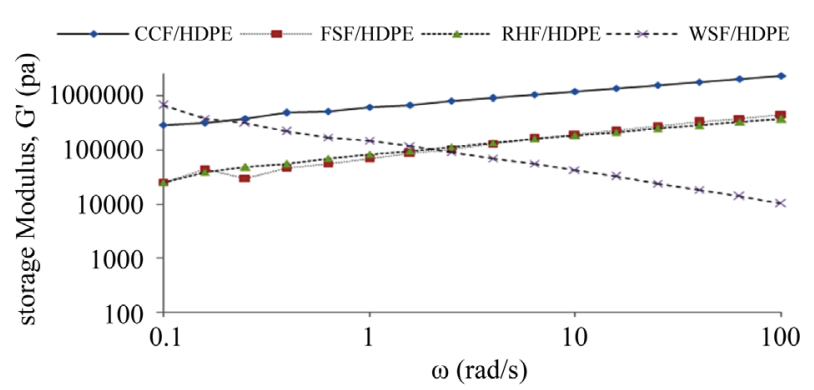

Figure 4. Storage modulus versus frequency. 
increased between composites with equal agro fiber load compared with that in the low frequency. The storage modulus behavior indicated that the ability to store the energy of external forces in the Corncob, Rice hull and Flax shives composites was increased while that for Walnut shell composites decreased with increasing angular frequency $(\omega)$. These differences in storage modulus of the agro fibers could be attributed to their differences in particle size distribution. The anomalous behavior of the sample WSF/HDPE composites could be explained thus: A higher number of smaller particles results in more particle-particle interactions and an increased resistance to flow. Clearly as shear rate increased, this effect became less marked, suggesting that any particleparticle interactions were relatively weak and broken down at high shear rates [40].

\subsection{Loss Modulus of Composites}

Figure 5 showed the variation of the loss ( $\left.G^{\prime \prime}\right)$ modulus with frequency $(\omega)$, for agro fiber filled HDPE composites at $170^{\circ} \mathrm{C}$. The loss modulus increased with increase in frequency and with filler load of $65 \%$ for all samples. The loss modulus was 200,000 GPa for CCF/HDPE, 63,000 GPa for WSF/HDPE and 29,000 GPa for RHF/ HDPE and FSF/HDPE at $0.1 \mathrm{rad} / \mathrm{s}$ respectively. Corncob composites showed greater ability of impact absorption, followed with walnut shell composites, in comparison with rice hull and flax shives composites respectively. The differences in loss modulus between the agro fiber by-products are attributable to differences in their particle size, particle size distribution. As frequency increased, the loss modulus differences increased between composites at same agro fiber load compared with that in the low frequency. The loss modulus behavior indicated that the ability of impact absorption was improved for all samples [41,42].

\subsection{Damping Factor $(\tan \delta)$}

Figure 6 showed the variation of damping factor with frequency. In order to obtain the information of how efficient the agro fiber composites lose energy to molecular rearrangements and internal friction, the relation between frequency and $\tan$ delta $\left(\tan \partial=\mathrm{G}^{\prime \prime} / \mathrm{G}^{\prime}\right)$ was obtained. In this composite system, the $\tan$ delta $(\tan \partial)$ decreased with the incorporation of $65 \%$ agro fiber load which is due mainly to the existence of effective interfacial bonding between agro fiber and HDPE matrix so that the viscoelastic energy dissipation in the composites was limited. It was also observed that with $65 \%$ (volume fraction) of the agro fibers, the tan $\partial$ became flat as the agro fibers restricts the relaxation of the polymer when force was applied. The $\tan \partial$ of all the agro fiber composite samples decreased monotonically to varying degrees in the whole

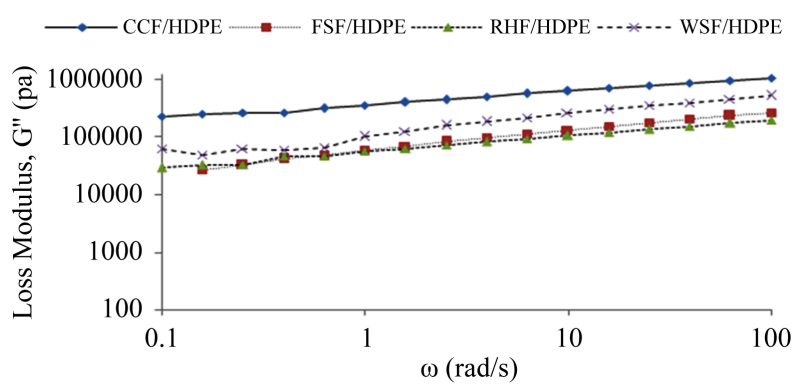

Figure 5. Loss modulus versus frequency.

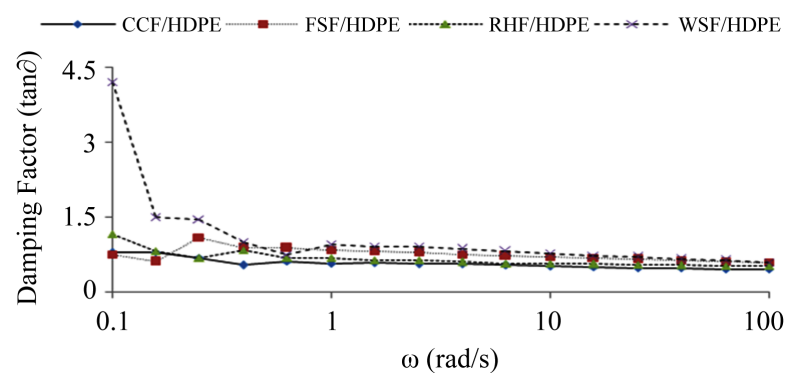

Figure 6. Damping factor $(\tan \delta)$ versus frequency.

frequencies range, and a flattened section at $\omega$ above $1 \mathrm{rad} / \mathrm{s}$. The differences in tan $\partial$ for all the samples could be attributed to the particle size, particle size distribution and bulk density of the agro fiber fillers. It is well known that, $\tan \partial$ is the ratio of $\mathrm{G}^{\prime \prime} / \mathrm{G}^{\prime}$ and with incorporation of fillers into polymer $G^{\prime}$ increased and $G^{\prime \prime}$ decreased due to the reduction of energy loss by porous filler, therefore the $\tan \partial$ decreased. The flattened section in the curve indicated the relaxation of the particles [43-45].

\subsection{Particle Size Distribution and Shape of Agro Fibers}

Figures 7 and 8 showed the particle size distribution and shape of the agro fibers used. Fibers sizes and shapes are the most important factors for composite materials. The effective surface area which may have influence on rheological properties depends on particle size and shape. Different types of fiber shapes could be seen. Most of the particles are round and angular in shape and small amount of particles are rod-type. It was observed that $70 \%$ of RHF was distributed in the range of $<0.125 \mathrm{~mm}$ (i.e., very fine particles). About $20 \%$ - 35\% of WSF was distributed in the range of $0.211-0.152 \mathrm{~mm}$ (i.e., medium particles). About 55\% of FSF was distributed in the range of $0.295 \mathrm{~mm}$ (i.e., coarse particles). About $10 \%$ $30 \%$ of CCF was distributed in the range of $0.211-$ $<0.125 \mathrm{~mm}$ (i.e., medium to very fine particles).

This inferred that the distribution frequency was not the same for all types of fibers. The unique change in the rheological behavior of the agro fiber composites was due mainly to differences in their particle size distribution 


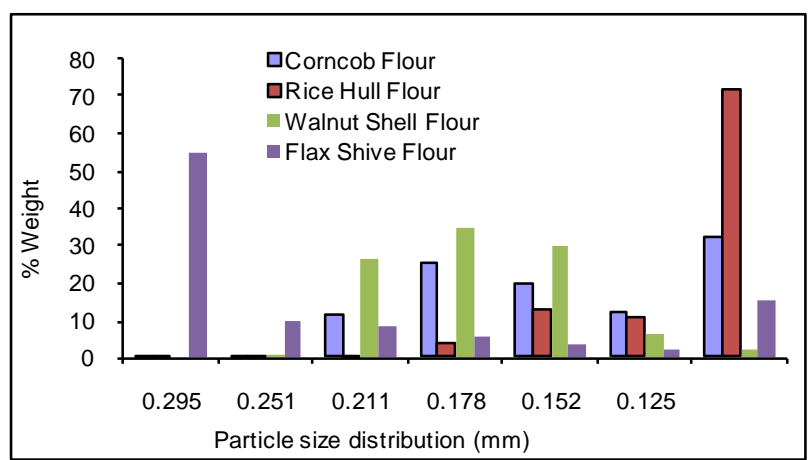

Figure 7. Particle size distribution of agro fibers.

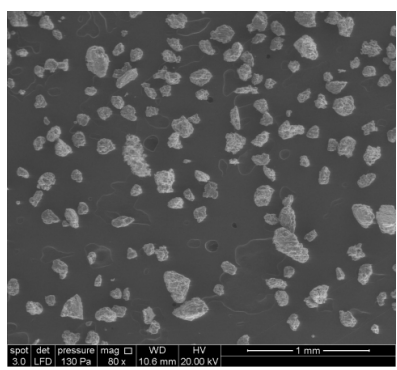

(a)

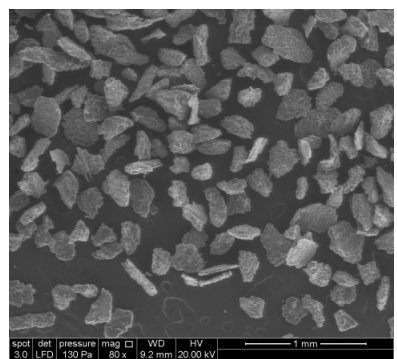

(c)

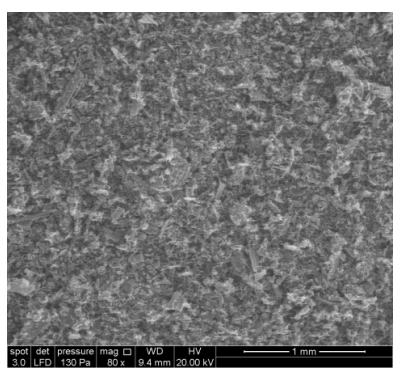

(b)

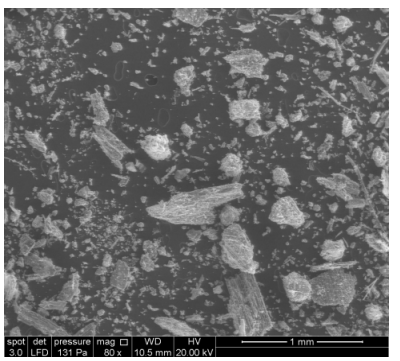

(d)
Figure 8. SEM: (a) CCF, (b) RHF, (c) WSF and (d) FSF.

and shape.

\subsection{SEM of Fractured Surfaces of Composites}

Figure 9 showed the scanning electron micro-graphs of the agro fibers/HDPE composites. It could be seen that there was complete fiber/matrix wetting or impregnation. This indicated the miscibility between the fibers with the HDPE matrix.

\section{Conclusion}

The rheological behavior of composites made by HDPE and different agro fiber by-products, such as Corncob, Rice hull, Flax shives and Walnut shell, has been investigated by a parallel-plate rheometer to understand the effects of agro fiber load (65 vol.\%) on composite properties. The results indicated considerable increase of complex viscosity, loss modulus and storage modulus at high filler load (65 vol.\%). The complex viscosities were

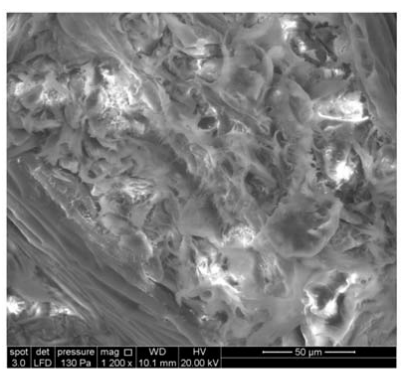

(a)

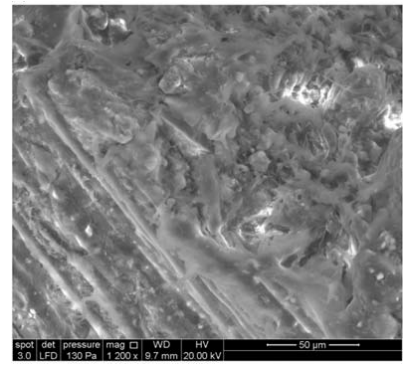

(c)

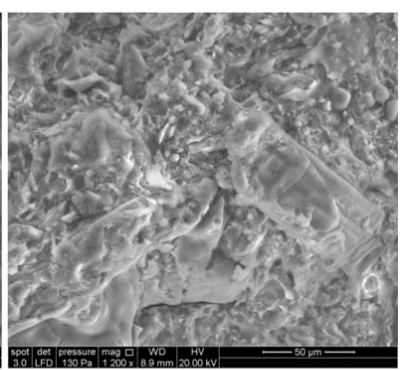

(b)

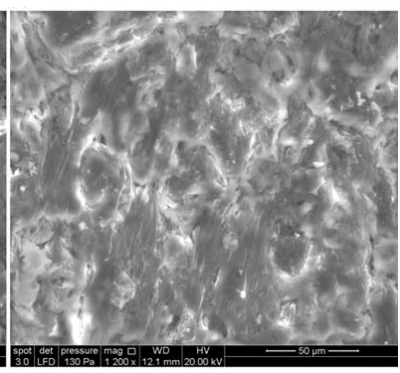

(d)
Figure 9. SEM micrographs of (a) CCF/HDPE (b) RHF/HDPE (c) FSF/HDPE and (d) WSF/HDPE composites.

quite high at the low frequency but decreased with increasing frequency indicating a shear thinning behavior of the agro fiber composites. With very fine filler, due to agglomeration of filler particles, complex viscosity is high. On the other hand, at very high particle sizes, due to difficulty of aligning fillers in the direction of flow, complex viscosity increases. The storage and loss modulus of the agro fiber composites increased with increasing angular frequency except for Walnut shell flour which exhibited unusual decrease in storage modulus with increasing frequency. The damping factor decreased with increasing frequency for all composites. The difference in the rheological behavior of the agro fibers/HDPE composites is due mainly to their particle size distribution.

\section{REFERENCES}

[1] B. Cheng, C. Zhou, W. Yu and X. Sun, "Evaluation of Rheological Parameters of Polymer Melts in Torque Rheometry,” Polymer Testing, Vol. 20, No. 7, 2001, pp. 811-818. http://dx.doi.org/10.1016/S0142-9418(01)00008-3

[2] A. H. Barnes, “A Handbook of Elementary Rheology,” University of Wales, Institute of Non-Newtonian Fluid Mechanics, Aberystwyth.

[3] J. George, R. Janardhan, J. S. Anand, S. S. Bhagawan and S. Thomas, "Melt Rheological Behavior of Short Pineapple Fiber Reinforced Low-Density Polyethylene Composites,” Polymer, Vol. 37, No. 24, 1996, pp. 5421-5431. http://dx.doi.org/10.1016/S0032-3861(96)00386-2

[4] A. L. N. da Silva, M. C. G. Rocha, M. A. R. Moraes, C. A. 
R. Valente and F. M. B. Coutinho, "Mechanical and Rheological Properties of Composites Based on Polyolefin and Mineral Additives,” Polymer Testing, Vol. 21, No. 1, 2002, pp. 57-60.

http://dx.doi.org/10.1016/S0142-9418(01)00047-2

[5] R. Guo, J. Azaiez and C. Bellehumeur, "Rheology of Fiber Filled Polymer Melts: Role of Fiber-Fiber Interactions and Polymer-Fiber Coupling," Polymer Engineering \& Science, Vol. 45, No. 3, 2005, pp. 385-399. http://dx.doi.org/10.1002/pen.20285

[6] Y. Qiang, W. Donglyang, J. Gotama and S. Bateman, "Wood Fiber Reinforced Polyethylene Composites with High Modulus and Impact Strength," Journal of Thermoplastic Composite Materials, Vol. 21, No. 3, 2008, pp. 195-208. http://dx.doi.org/10.1177/0892705708089472

[7] A. V. Shenoy, "Rheology of Highly Filled Polymer Systems,” Kluwer, London, 1999.

http://dx.doi.org/10.1007/978-94-015-9213-0

[8] A. George, M. S. Sreekala and S. Thomas, "A Review on Interface Modification and Characteristics of Natural Fiber Reinforced Plastic Composites,” Polymer Engineering \& Science, Vol. 41, No. 9, 2001, pp. 1471-1485.

[9] P. Wambua, J. Ivens and J. Verpoest, "Natural Fibers: Can They Replace Glass in Fiber Reinforced Plastic?” Composite Science Technology, Vol. 63, No. 9, 2003, pp. 1259-1264.

http://dx.doi.org/10.1016/S0266-3538(03)00096-4

[10] J. A. Youngquist, "The Marriage of Wood and Non-Wood Materials,” Forest Products, Vol. 45, No. 10, 1995, pp. 25-30.

[11] S. N. Maiti and M. R. Hassan, "Melt Rheological Properties of Polypropylene Wood Flour Composites," Journal of Applied Polymer Science, Vol. 37, No. 7, 1989, pp. 2019-2032.

http://dx.doi.org/10.1002/app.1989.070370721

[12] D. Basu, A. N. Banerjee and A. Misra, "Effect of Bark Flour on Melt Rheological Behavior of High-Density Polyethylene,” Journal of Applied Polymer Science, Vol. 46, No. 11, 2003, pp. 1999-2005.

http://dx.doi.org/10.1002/app.1992.070461112

[13] S. Thomas, M. S. Sreekala, M. G. Kumaran, S. Joseph and M. Jacob, "Oil Palm Fiber Reinforced PhenolFormaldehyde Composites: Influence of Fiber Surface Modifications on the Mechanical Performance,” Applied Composite Materials, Vol. 7, No. 5-6, 2000, pp. 295-329. http://dx.doi.org/10.1023/A:1026534006291

[14] S. N. Maiti, R. Subbarao and M. D. Ibrahim, "Effect of Wood Fibers on the Rheological Properties of i-PP/Wood Fiber Composites,” Journal of Applied Polymer Science, Vol. 91, No. 1, 2004, pp. 644-650.

http://dx.doi.org/10.1002/app.13157

[15] S. Dong, S. Sapieha and H. P. Schreiber, "Rheological Properties of Corona Modified Cellulose/Polyethylene Composites,” Journal of Applied Polymer Science, Vol. 32, No. 22, 1992, pp. 1734-1739. http://dx.doi.org/10.1002/pen.760322212

[16] J. Wu, D. Yu, C. M. Chan, J. G. Kim and Y. W. Mai, "Effect of Fiber Pretreatment Condition on the Interfacial Strength and Mechanical Properties of Wood Fiber/PP
Composites,” Journal of Applied Polymer Science, Vol. 76, No. 7, 2000, pp. 1000-1010.

http://dx.doi.org/10.1002/(SICI)1097-4628(20000516)76: 7<1000::AID-APP3>3.0.CO;2-X

[17] T. J. Keener, R. K. Stuart and T. K. Brown, "Maleated Coupling Agents for Natural Fiber Composites," Composites Part A: Applied Science and Manufacturing, Vol. 35, No. 3, 2004, pp. 357-362. http://dx.doi.org/10.1016/j.compositesa.2003.09.014

[18] S. G. Pardo, C. Bernal, A. Ares, M. J. Abad and J. Cano, "Rheological, Thermal and Mechanical Characterization of Fly-Ash Thermoplastic Composites with Different Coupling Agents,” Polymer Composites, Vol. 31, No. 10, 2010, pp. 1722-1730.

[19] V. Hristov and S. Vasilera, "Dynamic Mechanical and Thermal Properties of Modified Poly(propylene) Wood Fiber Composites," Macromolecular Materials and Engineering, Vol. 288, No. 10, 2003, pp. 798-806. http://dx.doi.org/10.1002/mame.200300110

[20] V. Hristov, E. Takacs and J. Vlachopoulos, "Viscoelastic Behavior of Highly Filled HDPE/Wood Flour Composites,” ANTEC Conference Proceedings, Vol. 72, No. 4, 2005, pp. 1331-1335.

[21] V. Hristov, E. Takacs and J. Vlachopoulos, "Surface Tearing and Wall Slip Phenomena in Extrusion of Highly Filled HDPE/Wood Flour Glass Hybrid Fiber-Reinforced Low-Density Polyethylene Composites. II. Chemical Modification,” Applied Polymer Science, Vol. 83, No. 2, 2003, pp. 443-450.

[22] T. Q. Li and M. P. Wolcott, "Rheology of HDPE-Wood Composites I. Steady State Shear and Extensional Flow," Composites Part A: Applied Science and Manufacturing, Vol. 35, No. 3, 2003, pp. 303-311.

http://dx.doi.org/10.1016/j.compositesa.2003.09.009

[23] T. Q. Li and M. P. Wolcott, "Rheology of Wood Plastics Melt. Part 1. Capillary Rheometry of HDPE Filled with Maple," Polymer Engineering \& Science, Vol. 45, No. 4, 2005, pp. 549-559. http://dx.doi.org/10.1002/pen.20308

[24] S. Mohanty, S. K. Verma and S. K. Nayak, "Rheological Characterization of HDPE/Jute Composite Melts," Journal of Applied Polymer Science, Vol. 99, 2006, pp. 14761484. http://dx.doi.org/10.1002/app.22661

[25] S. Mohanty and S. K. Nayak, "Rheological Characterization of HDPE/Sisal Fiber Composites,” Polymer Engineering \& Science, Vol. 47, No. 10, 2007, pp. 1634-1642. http://dx.doi.org/10.1002/pen.20847

[26] G. Kalaprasad and S. Thomas, "Melt Rheological Behavior of Intimately Mixed Short Sisal-Glass Hybrid FiberReinforced Low-Density Polyethylene Composites II. Chemical Modification,” Journal of Applied Polymer Science, Vol. 83, No. 2, 2003, pp. 443-450. http://dx.doi.org/10.1002/app.11976

[27] P. W. Balasuriya, L. Ye and Y. W. Mai, "Mechanical Properties of Wood Flake Polyethylene Composites. Part I: Effects of Processing Methods and Matrix Melt Flow Behavior," Composites Part A: Applied Science and Manufacturing, Vol. 32, No. 5, 2001, pp. 619-629. http://dx.doi.org/10.1016/S1359-835X(00)00160-3

[28] A. Q. Dong, Q. Yin, J. Xie, D. Li and Y. P. Yin, "Rheo- 
logical Behavior of $\mathrm{LDPE} / \mathrm{CaCO}_{3}$ Blends Containing EAA,” Polymer Composites, Vol. 30, No. 9, 2009, pp. 1212-1217. http://dx.doi.org/10.1002/pc.20680

[29] J. Z. Liang, "Effects of Extrusion Conditions on Melt Viscoelasticity during Capillary Flow of Low-Density Polyethylene,” Journal of Thermoplastic Composite Materials, Vol. 22, No. 1, 2000, pp. 99-110. http://dx.doi.org/10.1177/0892705708091610

[30] N. Othman, H. Ismail and M. Mariatti, "Effect of Compatibilizers on Mechanical and Thermal Properties of Bentonite Filled Polypropylene Composites,” Polymer Degradation and Stability, Vol. 91, No. 2, 2006, pp. 17611774.

http://dx.doi.org/10.1016/j.polymdegradstab.2005.11.022

[31] N. S. Balakrishna, H. Ismail and N. Othman, "The Effects of Rattan Filler Loading on Properties of Rattan PowderFilled Polypropylene Composites,” BioResources, Vol. 7, No. 4, 2012, pp. 5677-5690.

[32] N. E. Marcovich, M. M. Reboredo, J. Kenny and M. I. Aranguren, "Rheology of Particle Suspensions in Viscoelastic Media: Wood Flour Polypropylene Melts," Rheologica Acta, Vol. 43, No. 3, 2004, pp. 293-303. http://dx.doi.org/10.1007/s00397-003-0349-0

[33] M. J. Aranguren, E. Mora, J. V. DeGroot and C. W. Macosko, "Effect of Reinforcing Fillers on the Rheology of Polymer Melts,” Journal of Rheology, Vol. 36, No. 6, 1992, pp. 1165-1182. http://dx.doi.org/10.1122/1.550306

[34] D. N. Saheb and J. P. Jog, "Natural Fiber Polymer Composites: A Review," Advances in Polymer Technology, Vol. 18, No. 4, 1999, pp. 351-363.

[35] H. Azizi and I. Ghasemi, "Investigation on the Dynamic Melt Rheological Properties of Polypropylene/Wood Flour Composites,” Polymer Composites, Vol. 30, No. 4, 2009, pp. 429-435. http://dx.doi.org/10.1002/pc.20573

[36] S. Dong, S. Sapieha and H. P. Schreiber, "Rheological Properties of Corona Modified Cellulose/Polyethylene Composites,” Polymer Engineering \& Science, Vol. 32, No. 22, 1992, pp. 1734-1739. http://dx.doi.org/10.1002/pen.760322212

[37] K. Lozano, J. Bonilla-Rios and E. V. Barrera, “A Study on Nanofiber-Reinforced Thermoplastic Composites (II):
Investigation of the Mixing Rheology and Conduction Properties,” J. Applied Polymer Science, Vol. 80, No. 8, 2001, pp. 1162-1172. http://dx.doi.org/10.1002/app.1200

[38] S. Mohanty and S. K. Nayak, "Mechanical and Rheological Characterization of Treated Jute-HDPE Composites with a Different Morphology," Journal of Reinforced Plastics and Composites, Vol. 25, No. 13, 2006, pp. 1419-1439. http://dx.doi.org/10.1177/0731684406066676

[39] I. Noranizan and I. Ahmad, "Effect of Fiber Loading and Compatibilizer on Rheological and Morphological Behaviors," Open Journal of Polymer Chemistry, Vol. 2, No. 2, 2012, pp. 31-41.

[40] J. Son, D. J. Gardner, S. O’Neill and C. Metaxas, “Understanding the Viscoelastic Properties of Extruded Polypropylene Wood Plastic Composites,” Journal of Applied Polymer Science, Vol. 89, No. 6, 2003, pp. 1638-1644. http://dx.doi.org/10.1002/app.12372

[41] K. C. M. Nair, P. P. Kumar, S. Thomas, S. C. Schit and K. Ramamurthy, "Rheological Behavior of Short Sisal FiberReinforced Polystyrene Composites," Composites Part A: Applied Science and Manufacturing, Vol. 31, No. 11, 2000, pp. 1231-1242.

[42] T. G. Mezger, "Rheology Handbook,” 2nd Edition, Vincentz Network, Hannover, 2006.

[43] S. Mir, T. Yasin, T. J. Halley, H. M. Siddiqi and T. Nicholson, "Thermal, Rheological, Mechanical and Morphological Behavior of HDPE/Chitosan Blend," Carbohydrate Polymers, Vol. 83, No. 2, 2011, pp. 414-421.

[44] M. Z. Pan, S. Y. Zhang and D. G. Zhou, "Preparation and Properties of Wheat Straw Fiber-Polypropylene Composites. Part II. Investigation of Surface Treatments on the Thermo-Mechanical and Rheological Properties of the Composites," Journal of Composite Materials, Vol. 44, No. 9, 2010, pp. 1061-1074.

[45] S. H. Tabatabaei, P. J. Carreau and A. Ajji, "Rheological and Thermal Properties of Blends of a Long-Chain Branched Polypropylene and Different Linear Polypropylene,” Chemical Engineering Science, Vol. 64, No. 22, 2009, pp. 4719-4731. http://dx.doi.org/10.1016/j.ces.2009.04.009 